\title{
Transcriptomic Analysis of Histone Methyltransferase Setd7 Knockdown and Phenethyl Isothiocyanate in Human Prostate Cancer Cells
}

\author{
CHAO WANG ${ }^{1,2 \#}$, DAVIT SARGSYAN ${ }^{1,2,3 \#}$, CHENGYUE ZHANG $^{1,2,3}$, \\ RENYI WU ${ }^{1,2}$, YUQING YANG ${ }^{1,2,3}$ and AH-NG KONG ${ }^{1,2}$ \\ ${ }^{1}$ Department of Pharmaceutics, ${ }^{2}$ Center for Phytochemical Epigenome Studies and \\ ${ }^{3}$ Graduate Program of Pharmaceutical Sciences, Ernest Mario School of Pharmacy, \\ Rutgers, the State University of New Jersey, Piscataway, NJ, U.S.A.
}

\begin{abstract}
Background/Aim: Transcriptomic analysis was performed to evaluate the differential gene expression profiles of Setd7 knockdown (KD) and the effects of phenethyl isothiocyanate (PEITC) in human prostate cancer $(P C a)$ LNCaP cells. Materials and Methods: RNA isolated from wild-type and Setd7-KD LNCaP cells in the presence or absence of PEITC was subjected to microarray analysis followed by Ingenuity ${ }^{\circledR}$ Pathway Analysis (IPA). Results: Setd 7 KD impacted a larger set of genes and caused a higher fold change compared to PEITC treatment. Several signaling pathways were altered particularly inflammation-related TNFR signaling and PTEN/PI3K/AKT signaling by Setd7 KD and PEITC. Interestingly, PEITC and Setd7 KD at a small subset of genes that could be potential molecular targets. Conclusion: This study offers new insights into the mechanisms of action of the epigenetic modifier Setd7 and the effects of PEITC treatment in PCa cells and enhances our understanding of the potential cancer preventive/treatment effects of isothiocyanate compounds such as PEITC in PCa.
\end{abstract}

In recent years, many epidemiological studies have suggested that the consumption of cruciferous vegetables can

This article is freely accessible online.

\#These Authors contributed equally to this study.

Correspondence to: Professor Ah-Ng Tony Kong, Department of Pharmaceutics, Center for Phytochemical Epigenome Studies, Ernest Mario School of Pharmacy, Rutgers, the State University of New Jersey, 160 Frelinghuysen Road, Piscataway, New Jersey 08854, U.S.A. Tel: +1 8484556369, Fax: +1 7324553134, e-mail: KongT@pharmacy.rutgers.edu

Key Words: Microarray, prostate cancer, histone methyltransferase, isothiocyanates, PEITC, Setd7. reduce the incidence of PCa (1). Isothiocyanates (ITCs), such as phenethyl isothiocyanate (PEITC), have been reported to have chemoprotective, antitumor, anti-inflammatory, and HDAC- and/or DNA methyltransferase (DNMT)-inhibitory properties (2-11). In addition, PEITC reduced the risk of $\mathrm{PCa}$ in mouse models and suppressed the growth of $\mathrm{PCa}$ cell xenografts in vivo (12-14). PCa is one of the most common cancers among men in the United States. Approximately 1 out of 39 men will die of prostate cancer, and the risk increases as men age. Thus, new strategies are required to prevent, or slow the initiation and progression of $\mathrm{PCa}$. Recent studies revealed that PEITC and Setd7 affect many targets involved in various signaling pathways. However, the mechanism of interaction of PEITC and Setd7 in PCa has not yet been previously explored.

Accumulating evidence suggests that epigenetic regulation contributes to cancer initiation and progression and may precede genetic mutation. Setd7 (also known as Set7/9) is a SET (Su(var)3-9, Enhancer-of-zeste, Trithorax) domaincontaining lysine methyltransferase that targets lysine 4 on histone H3 (H3K4). Setd7 exhibits monomethyltransferase activity and promotes an open chromatin architecture, transcriptional activation and target genes, expression (15). Gene transcription is regulated genetically through mutations and epigenetically through covalent histone modification and DNA methylation that either promote or restrict the gene promoters' accessibility to components of the basic transcriptional machinery $(16,17)$. Recently, many studies have shown that Setd 7 plays multiple roles in regulating, not only histone assembly but also non-histone protein stability and/or activity, including that of Dnmt1, p65, ER $\alpha$, AR, and Pcaf (1822). Several groups have shown that Setd7 contributes to inflammation through interactions with components of the NF$\mathrm{kB}$ signaling pathway, thus leading to the down-regulation or up-regulation of NF-kB activity depending on the cell type and/or physiological conditions (20, 23-25). 
In prostate cancer $(\mathrm{PCa})$, Setd7 methylates the androgen receptor (AR), shows pro-proliferative and anti-apoptotic activity, and exhibits up-regulated nuclear expression (26). Recent whole-transcriptome sequencing results indicated that Setd 7 has frameshift mutations in castration-resistant prostate cancer (CRPC), which could lead to altered chromatin accessibility in co-transcriptional RNA processing (27). Only a few publications exist on Setd7 and $\mathrm{PCa}$, but increasing evidence indicates the importance and potential of Setd7 in $\mathrm{PCa}$ therapeutics and diagnostics. A spate of recent studies on Setd7 and PEITC revealed that many targets involved in various signaling pathways can be influenced by these factors. However, whether PEITC affects epigenetic regulation by Setd7 in PCa and the global transcriptomic profiling has not yet been previously explored. In this study, Affymetrix ${ }^{\mathrm{TM}}$ oligonucleotide microarrays were used to analyze differential gene expression and signaling pathways induced by PEITC and the impact of Setd7 KD in human LNCaP cells.

\section{Materials and Methods}

Materials. RPMI 1640 medium, fetal bovine serum (FBS), penicillin-streptomycin $(10,000 \mathrm{U} / \mathrm{ml})$, puromycin, versene, and trypsin-EDTA were supplied by Gibco (Grand Island, NY, USA). PEITC and dimethyl sulfoxide (DMSO) were purchased from Sigma-Aldrich (St. Louis, MO, USA).

Cell culture and treatment. The PCa LNCaP cell line was obtained from the American Type Culture Collection (ATCC; Manassas, VA, USA) and cultured in RPMI 1640 with $10 \% \mathrm{FBS}$ at $37^{\circ} \mathrm{C}$ in a humidified 5\% $\mathrm{CO}_{2}$ atmosphere. Cells were grown to approximately $80 \%$ confluence and treated with medium containing PEITC $(5 \mu \mathrm{M})$ at the indicated concentrations for $24 \mathrm{~h}$ or other indicated times as previously described (28). DMSO $(0.1 \%)$ was used as the vehicle control.

Setd7 knockdown in LNCaP cells. Lentivirus-mediated short hairpin RNAs (shRNAs) were used to establish stable mock (control, shMock) and Setd7 knockdown (sh-SETD7) LNCaP cells. The shRNA clone sets were obtained from GeneCopoeia (Rockville, MD, USA), and lentiviral-mediated transduction was performed according to the manufacturer's protocol as previously described (28).

RNA isolation and oligonucleotide microarray analyses for transcriptome profiling. Total RNA was extracted from cells using a RNeasy Mini kit (Qiagen, Valencia, CA, USA). The quality and quantity of the extracted RNA samples were determined using an Agilent 2100 Bioanalyzer and a NanoDrop instrument, respectively. A total of 4 RNA samples [1 sample per group x 4 groups (DMSOor PEITC-treated LNCaP and LNCaP Setd7-KD cells)] were sent to RUCDR for subsequent technical procedures including quality control, RNA concentration measurement, cDNA synthesis, cRNA biotin labeling, hybridization, and scanning of the arrays. In brief, the samples were applied to the GeneChip Human Gene 2.0 ST Array (Affymetrix, Santa Clara, CA, USA), which contains probes for the detection of $>40,000$ transcripts, $>25,000$ genes, and $>11,000$ long intergenic non-coding RNA (lincRNA) transcripts. The expression value for each gene was determined by calculating the average of differences in intensity (perfect match intensity minus mismatch intensity) between its probe pairs and was stored in CEL data files. Computational analyses of microarray data. CEL data files were imported into $R$ (version 3.4.2) using the package oligo (29). Pseudo-image plots were used to assess the spatial distribution of the data on the chips. Due to differences in the magnitude of the readings, rank-transformed data were plotted to avoid the masking of spatial features that may have been present on the array (Figure 1A). The data were normalized by applying the robust multiple average (RMA) algorithm ( $\mathrm{R}$ function rma from package oligo) for background subtraction, quantile normalization, and summarization (via median-polish) $(30,31)$ and annotated with the pd.hugene.2.0.st $\mathrm{R}$ package (Figure 1B). The normalized values for the 150 top differentially expressed genes across 4 groups (WT, KD, WT PEITC, and KD PEITC) are presented in Figure 2.

Ingenuity Pathway Analysis (IPA). Isoforms with $\log 2$ fold changes greater than 0.5 were subjected to Ingenuity Pathway Analysis (IPA 4.0, Ingenuity Systems, www.Ingenuity.com). The input isoforms were mapped to IPA's knowledgebase, and the relevant biological functions, networks, and pathways related to Setd7 knockdown and PEITC treatments were identified.

Quantitative polymerase chain reaction ( $q P C R$ ) for microarray data validation. $\mathrm{qPCR}$ was used to validate selected differentially expressed genes detected by microarrays. Following the manufacturer's instructions, first-strand complementary DNA was synthesized from 1 $\mu \mathrm{g}$ of RNA using TaqMan ${ }^{\circledR}$ Reverse Transcription Reagents (Applied Biosystems, Carlsbad, CA, USA). qPCR analysis was performed on a QuantStudio $^{\text {TM }} 5$ Real-Time PCR System (Applied Biosystems) using SYBR Green PCR Master Mix (Applied Biosystems) and complementary DNA as the template. The sequences of the primers used in PCR amplifications are listed in Table I. The PCR conditions were as follows: initial denaturation for $10 \mathrm{~min}$ at $95^{\circ} \mathrm{C}$ followed by 40 cycles at $95^{\circ} \mathrm{C}$ for $15 \mathrm{sec}$ and $1 \mathrm{~min}$ at $60^{\circ} \mathrm{C}$. Melting curve analysis was performed to ensure the specificity of the products. The relative gene expression levels were normalized to the GAPDH level using the $2^{-\Delta \Delta \mathrm{CT}}$ formula $\left(\Delta \Delta \mathrm{C}_{\mathrm{T}}=\Delta \mathrm{C}_{\mathrm{T}}\right.$ sample $-\Delta \mathrm{C}_{\mathrm{T}}$ control $)$.

Statistical analysis. Statistical significance was assessed with oneway ANOVA followed by Dunnett's post-hoc test among multiple experimental groups and Student's $t$-test between two experimental groups using GraphPad PRISM software. The values are presented as the means \pm standard deviation (SD), and $p$-values less than 0.05 were considered statistically significant.

\section{Results}

Top differentially expressed genes and canonical pathways affected in LNCaP Setd7-KD cells and LNCaP cells. Setd7, an epigenetic modifier plays a prominent role in histone and non-histone protein lysine methylation. To understand the effects of Setd7 KD in LNCaP PCa cells, the gene expression profile of wild-type LNCaP cells was compared to that of Setd7-KD cells. A total of 651 differentially expressed genes showed a $\log 2$ fold change greater than 0.5 or less than -0.5 . The top 10 genes most down-regulated by Setd7 KD and the top 10 genes most up-regulated by Setd7 $\mathrm{KD}$ are presented in Table II. These genes had dramatic fold changes (as low as 0.150 -fold to as high as 28.06 -fold) when 
A

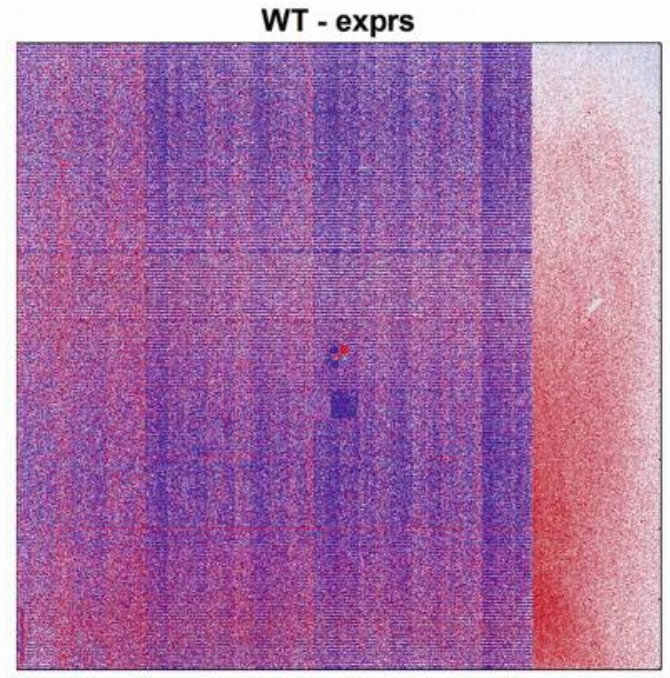

KD - exprs

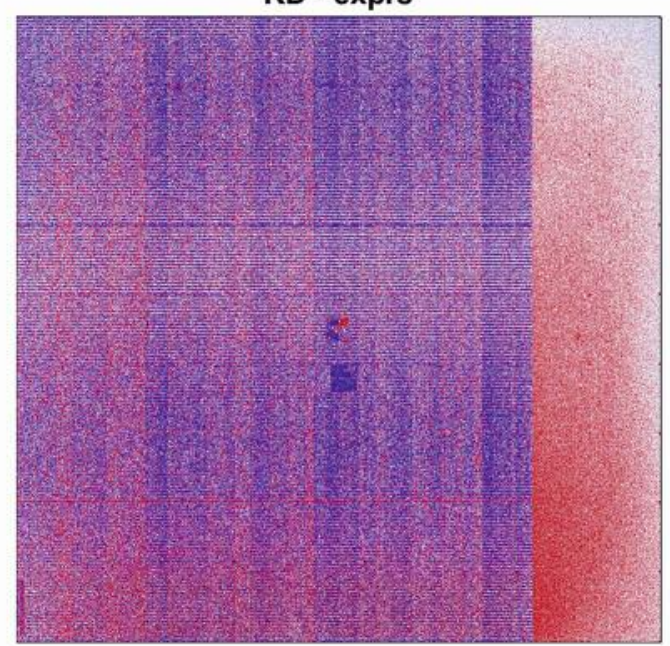

B

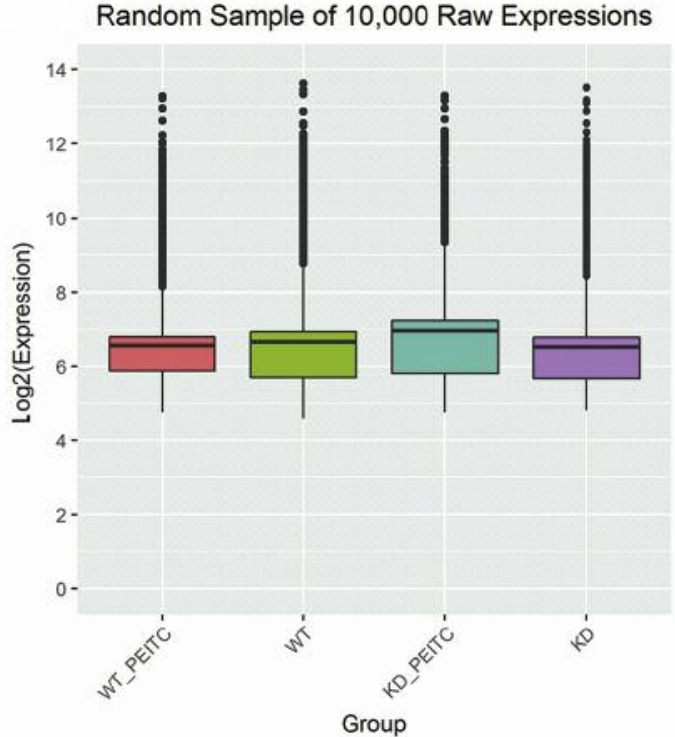

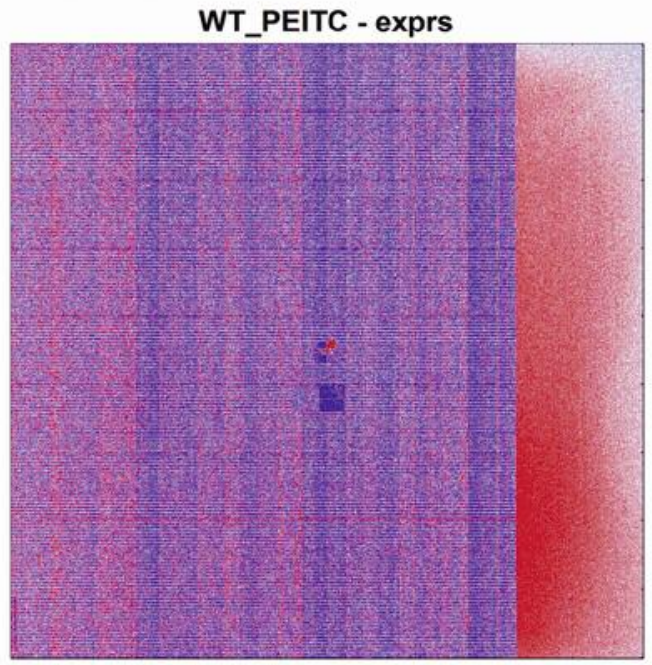

KD_PEITC - exprs

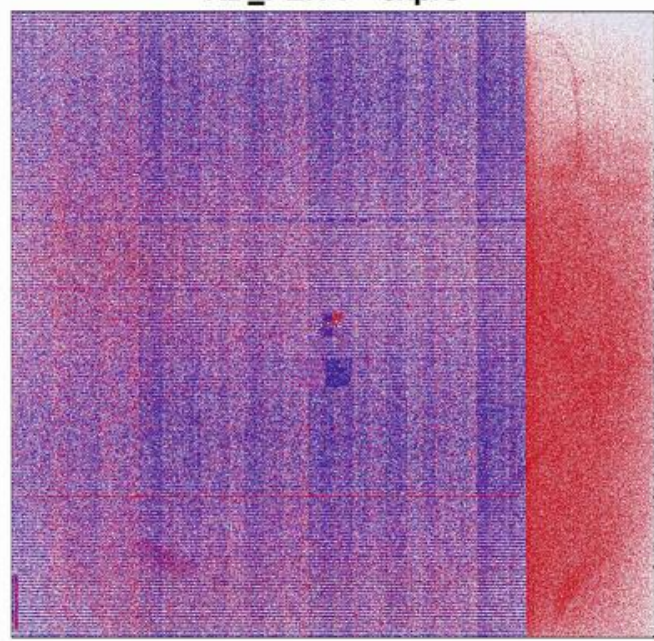

Normilazed Annotated Genes

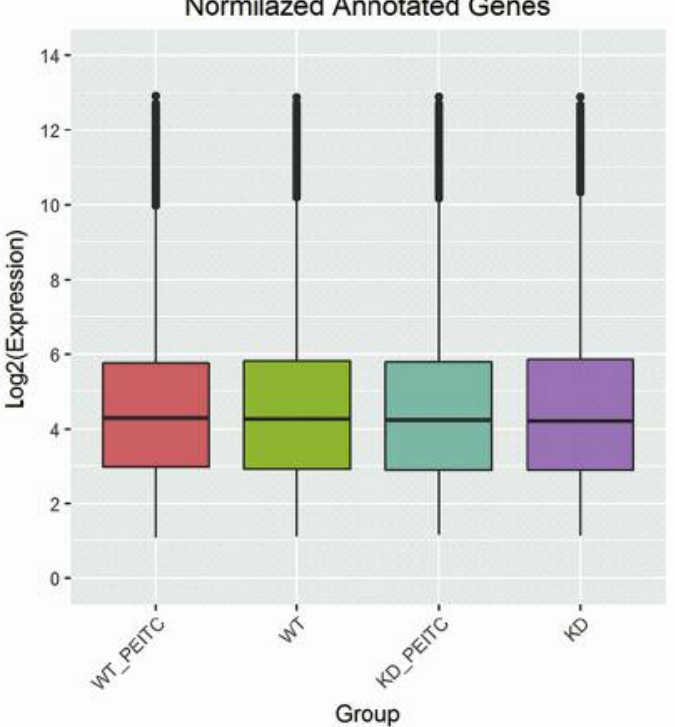

Figure 1. Pseudo-image plots were used to assess the spatial distribution of the data on the chips. (A) Rank transformed data. (B) Normalized annotated data. 


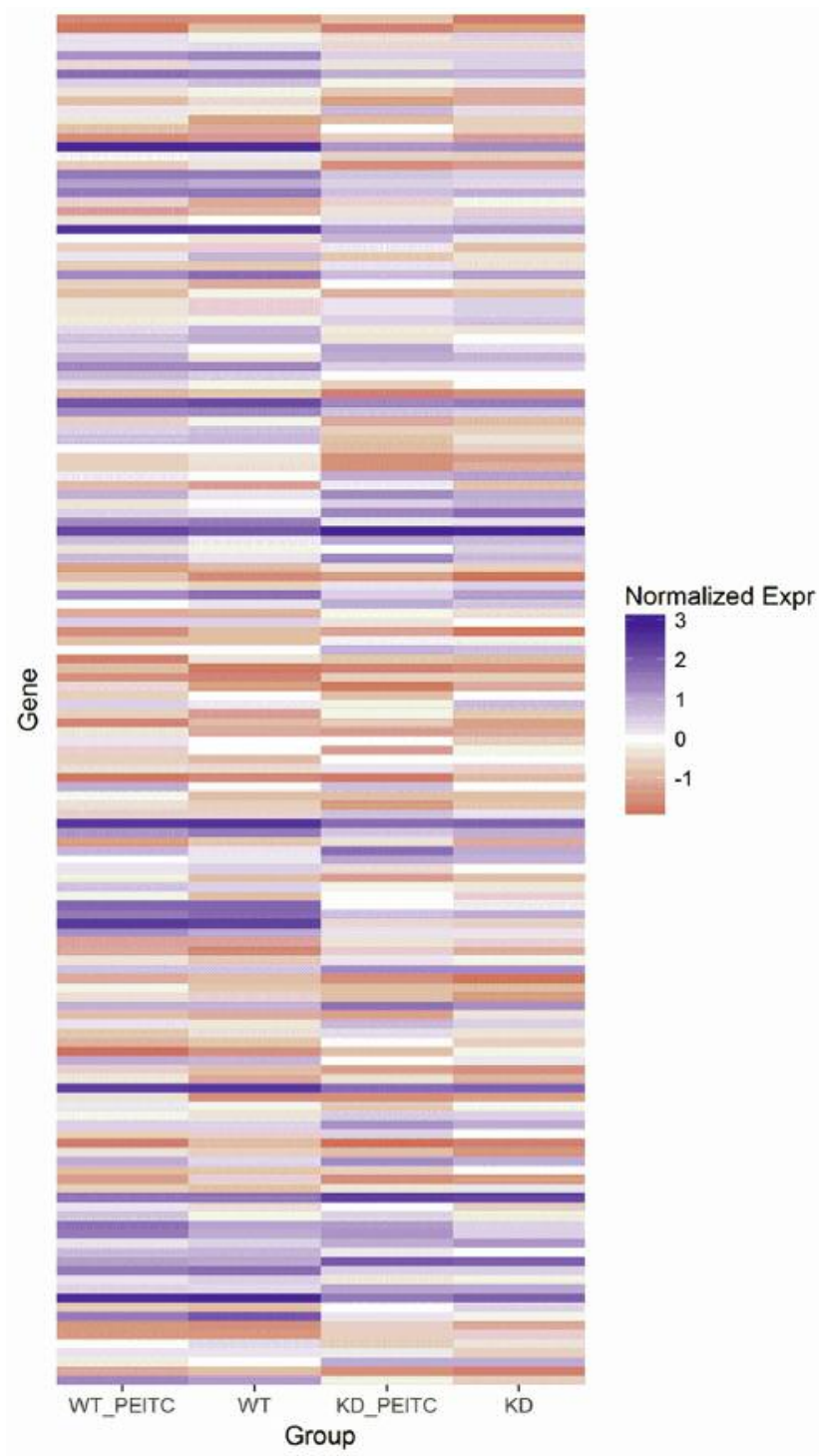

Figure 2. The 150 top differentially expressed genes with normalized values across 4 groups (WT, KD, WT PEITC, and KD PEITC).

Setd7 expression was KD. Interestingly, the tumor suppressor gene Rarres 3 and the antioxidant gene Sod2 were up-regulated 28.06-fold, and 5.66-fold, respectively, when Setd7 was knocked down. Canonical pathway analysis in IPA was used to understand the possible biological functions associated with these differentially expressed genes. Based on the ratio between the number of differentially expressed genes within our datasets belonging to a given pathway and the total number of reference genes in the corresponding pathway in the IPA knowledgebase, Fisher's exact test was used to identify significantly affected canonical pathways. Using a $p$-value cutoff of less than 0.05 , a total of 377 canonical pathways were identified as significantly
Table I. The primers used in $q P C R$.

\begin{tabular}{|c|c|}
\hline Primer & Sequence $\left(5^{\prime} \rightarrow 3^{\prime}\right)$ \\
\hline SI For & AAATCAGACACCCAATCGTTTCC \\
\hline SI Rev & GGGCAACCTTCACATCATACAA \\
\hline PCDHB13 For & CACCCTACTAACGGAGAGACC \\
\hline PCDHB13 Rev & GTCATTGACATCGGCGATCAG \\
\hline CD24 For & CTCCTACCCACGCAGATTTATTC \\
\hline CD24 Rev & AGAGTGAGACCACGAAGAGAC \\
\hline SDC4 For & GGACCTCCTAGAAGGCCGATA \\
\hline SDC4 Rev & AGGGCCGATCATGGAGTCTT \\
\hline RAB31 For & GGGGTTGGGAAATCAAGCATC \\
\hline RAB31 Rev & GCCAATGAATGAAACCGTTCCT \\
\hline GADD45B For & TACGAGTCGGCCAAGTTGATG \\
\hline GADD45B Rev & GGATGAGCGTGAAGTGGATTT \\
\hline SACS For & GCGCGATGTGAAGGAACGTA \\
\hline SACS Rev & TCTCCAATCTTGATCCAGTCAGA \\
\hline GH2 For & GACACAAAATCGCACAACGATG \\
\hline GH2 Rev & GGGCAGCTAGAAGCCACAG \\
\hline ID1 For & CTGCTCTACGACATGAACGG \\
\hline ID1 Rev & GAAGGTCCCTGATGTAGTCGAT \\
\hline LXN For & GAAATCCCGCCGACCAACTA \\
\hline LXN Rev & CTGCACCTCAAACACCCTGT \\
\hline LRRTM1 For & TCGGGCAACGAGATCGAGTA \\
\hline LRRTM1 Rev & GCTTGTCAGGGACTTCCAAGA \\
\hline FCRL6 For & CTGGGCTTTACTGGTGTGAGG \\
\hline FCRL6 Rev & TGAGCACAGGACGGGATACA \\
\hline THSD7A For & TCAGTGTCAGCCCGTGATTTC \\
\hline THSD7A Rev & GATGCACGCTATCTCCCTCA \\
\hline APOM For & GCTACCATCCGCATGAAAGAT \\
\hline APOM Rev & CTGGCCTGTCTCATTCAGCA \\
\hline ARMC12 For & CAAAAGCGTAGTCAGCCTGG \\
\hline ARMC12 Rev & GATGCAGATGGGTGAGTTGC \\
\hline TKTL1 For & ACAAGCAGTCAGATCCAGAGA \\
\hline TKTL1 Rev & TAGCTGGCCCTGTCGAAGTA \\
\hline ZNF235 For & CCTCTTACCCAGCGTAGTATTCA \\
\hline ZNF235 Rev & CCTGAGCTATAACTGGTGTCCT \\
\hline TPM3 For & TGAAAACCGGGCCTTAAAAGAT \\
\hline TPM3 Rev & GATCACCAACTTACGAGCCAC \\
\hline DCAF4L1 For & CAGCGACCAGCTCTTCGTAG \\
\hline DCAF4L1 Rev & TGGGGACGTAGAGGTTTCTGA \\
\hline CBLN2 For & GGCGTTTGGAGCAACTTCG \\
\hline CBLN2 Rev & TTCAAGGCCAGGGTCGTTC \\
\hline TAS2R19 For & GAAGATGCGGCTCCATAGCAA \\
\hline TAS2R19 Rev & TGGCAAAGCAGGAGTACAAGT \\
\hline OR9A2 For & ATGTATCGCTCAACTTTTCCTGT \\
\hline OR9A2 Rev & CCСАTGACACTATТАССАСССАА \\
\hline
\end{tabular}

correlated with Setd7 KD in LNCaP cells. Table III displays the 10 most significant pathways, $\log (p$-value) scores, the ratio of affected genes to total genes in that particular pathway, and details regarding significantly differentially expressed genes. The top 3 canonical pathways significantly influenced by Setd7 KD were "Death Receptor Signaling", "TNFR2 Signaling", and "Acute Phase Response Signaling". Based on these results, Setd7 KD significantly affected the expression of many genes. 
Table II. Top 10 down-regulated and up-regulated genes in LNCaP Setd7-KD cell compared to LNCaP cell. Fold change larger than 1 indicates higher expression in LNCaP Setd7-KD cell. Fold change smaller than 1 indicates lower expression in LNCaP cell.

\begin{tabular}{|c|c|c|c|}
\hline Gene ID & Gene name & Fold Change & Location \\
\hline \multicolumn{4}{|c|}{ Down-regulated } \\
\hline$B S G$ & Basigin (Ok blood group) & 0.150 & Plasma Membrane \\
\hline PLOD2 & Procollagen-lysine,2-oxoglutarate 5-dioxygenase 2 & 0.197 & Cytoplasm \\
\hline DNAJC15 & DnaJ heat shock protein family (Hsp40) member $\mathrm{C} 15$ & 0.213 & Cytoplasm \\
\hline TSPAN6 & Tetraspanin 6 & 0.242 & Plasma Membrane \\
\hline$S C D$ & Stearoyl-CoA desaturase & 0.248 & Cytoplasm \\
\hline$T M E F F 2$ & Transmembrane protein with EGF like and two follistatin like domains 2 & 0.268 & Cytoplasm \\
\hline$A C K R 3$ & Atypical chemokine receptor 3 & 0.274 & Plasma Membrane \\
\hline DSEL & Dermatan sulfate epimerase-like & 0.278 & Extracellular Space \\
\hline TUBB4A & Tubulin beta 4A class IVa & 0.289 & Cytoplasm \\
\hline TMPRSS2 & Transmembrane protease, serine 2 & 0.311 & Plasma Membrane \\
\hline \multicolumn{4}{|c|}{ Up-regulated } \\
\hline RARRES3 & Retinoic acid receptor responder 3 & 28.06 & Cytoplasm \\
\hline$G B P 2$ & Guanylate binding protein 2 & 12.76 & Cytoplasm \\
\hline ID1 & Inhibitor of DNA binding $1, \mathrm{HLH}$ protein & 8.43 & Nucleus \\
\hline$J U N B$ & JunB proto-oncogene, $\mathrm{AP}-1$ transcription factor subunit & 7.47 & Nucleus \\
\hline NMI & N-myc and STAT interactor & 7.31 & Cytoplasm \\
\hline BIRC3 & Baculoviral IAP repeat containing 3 & 7.22 & Cytoplasm \\
\hline OSMR & Oncostatin $\mathrm{M}$ receptor & 6.24 & Plasma Membrane \\
\hline CASP4 & Caspase 4 & 5.77 & Cytoplasm \\
\hline SOD2 & Superoxide dismutase 2 & 5.66 & Cytoplasm \\
\hline TNFAIP3 & TNF alpha induced protein 3 & 5.44 & Nucleus \\
\hline
\end{tabular}

Table III. The 10 most significant canonical pathways regulated by Setd7 knockdown compared to normal LNCaP cell. Genes in bold are downregulated in LNCaP Setd7-KD cells.

\begin{tabular}{|c|c|c|c|}
\hline Canonical pathways & $\begin{array}{c}- \text { Log } \\
(p \text {-Value })\end{array}$ & Ratio & Target genes \\
\hline Death receptor signaling & 5.6 & $27 / 76(0.355)$ & $\begin{array}{c}\text { MAP2K4, TNFSF 10, PARP12, MAP } 3 K 5, N F K B 1, P A R P 9, I K B K B, N F K B I A, \\
\text { TNFSF15, CASP8, BIRC3, PARP14, CASP10,TNFRSF21, TNFRSF1A, ACTB, } \\
\text { PARP8, TBK1, PARP3, NFKB2, XIAP, DAXX,TRAF2, RIPK1, TNF, CASP7, HSPB1 }\end{array}$ \\
\hline TNFR2 signaling & 4.26 & $12 / 25(0.480)$ & $\begin{array}{c}M A P 2 K 4, I K B K B, T R A F 2, N F K B I A, J U N, T N F A I P 3 \\
T B K 1, N F K B 2, N F K B 1, B I R C 3, T N F, \text { XIAP }\end{array}$ \\
\hline $\begin{array}{l}\text { Acute phase response } \\
\text { signaling }\end{array}$ & 3.67 & 25/85 (0.294) & $\begin{array}{c}\text { MAP2K4, IL6ST, PIK3CA, FN1, TNFRSF1A, PDPK1, CEBPB, NFKB2, STAT3, } \\
\text { MAP3K5, NFKB1, HNRNPK, C5, HMOX1, IKBKB, TRAF2, SOD2, } \\
\text { JUN, RBP7, NFKBIA, RIPK1, MAP2K2, SOCS2, OSMR, TNF }\end{array}$ \\
\hline $\begin{array}{l}\text { Neuroinflammation } \\
\text { signaling pathway }\end{array}$ & 3.4 & $38 / 155(0.245)$ & $\begin{array}{l}\text { MAP } 2 K 4, \text { B2M, TRAF3, PIK3CA, ICAM1, HLA-A, TGFBR3, HLA-B, MFGE8, } \\
\text { NFKB1, TGFBR2, HMOX1, IKBKB, SOD2, JUN, FGFR4, TLR7, CASP8, STAT1, } \\
\text { BIRC3, TNFRSF1A, CREB3, IFNGR2, GABBR1, IFNGR1, TBK1, NFKB2, PLA2G2A, } \\
\text { ACVR1B, XIAP, APP, RIPK1, APH1A, GLUL, PTGS2, TNF, ACVR2A, IRAK2 }\end{array}$ \\
\hline $\begin{array}{l}\text { Agrin interactions at } \\
\text { neuromuscular junction }\end{array}$ & 3.15 & $15 / 44(0.341)$ & $\begin{array}{c}\text { MAP2K4, ARHGEF7, ACTB, ITGA2, ITGA6, LAMC1, PTK2, } \\
\text { ITGB2, JUN, ARHGEF6, UTRN, DAG1,ERBB2, CTTN, EGFR }\end{array}$ \\
\hline TNFR1 signaling & 3.15 & $15 / 44(0.341)$ & $\begin{array}{l}\text { MAP2K4, TNFRSF1A, TNFAIP3, NFKB2, NFKB1, XIAP, IKBKB, } \\
\text { TRAF2, RIPK1, JUN, NFKBIA, CASP8, BIRC3,TNF, CASP7 }\end{array}$ \\
\hline $\begin{array}{l}\text { Role of RIG1-like receptors } \\
\text { in antiviral innate immunity }\end{array}$ & 3.02 & $10 / 24(0.417)$ & $\begin{array}{c}I K B K B, T R A F 3, T R A F 2, R I P K 1, N F K B I A, T B K 1 \\
N F K B 2, C A S P 8, N F K B 1, C A S P 10\end{array}$ \\
\hline OX40 signaling pathway & 3.02 & $11 / 28(0.393)$ & $\begin{array}{c}B 2 M, \text { MAP2K4, BCL2L1, TRAF3, TRAF2, NFKBIA, } \\
J U N, \text { HLA-A, HLA-B, NFKB2, NFKB1 }\end{array}$ \\
\hline $\mathrm{T}$ Helper cell differentiation & 2.87 & $11 / 29(0.379)$ & $\begin{array}{l}\text { IL6ST, TGFBR2, TNFRSF1A, HLA-A, HLA-B, } \\
\text { IFNGR2, IFNGR1, STAT3, STAT1, BCL6, TNF }\end{array}$ \\
\hline $\begin{array}{l}\text { Induction of apoptosis } 1 \\
\text { by HIV }\end{array}$ & 2.78 & $16 / 52(0.308)$ & $\begin{array}{c}\text { MAP2K4, TNFRSF1A, SLC25A3, MAP3K5, NFKB2, NFKB1, XIAP, } \\
\text { BCL2L1, IKBKB, DAXX, TRAF2, RIPK1, NFKBIA, CASP8, BIRC3,TNF }\end{array}$ \\
\hline
\end{tabular}


Table IV. Top 10 down-regulated and up-regulated genes in LNCaP Setd7-KD cell treated by PEITC compared to DMSO group. The expression of these genes in DMSO group was set to 1.

\begin{tabular}{|c|c|c|c|}
\hline Gene ID & Gene name & Fold Change & Location \\
\hline \multicolumn{4}{|c|}{ Down-regulated } \\
\hline TIMP1 & TIMP metallopeptidase inhibitor 1 & 0.369 & Extracellular space \\
\hline$T N K S$ & Tankyrase & 0.392 & Nucleus \\
\hline$H L A-D R B 1$ & Major histocompatibility complex, class II, DR beta 1 & 0.403 & Plasma membrane \\
\hline GNAI2 & $\mathrm{G}$ protein subunit alpha i2 & 0.413 & Plasma membrane \\
\hline$H 6 P D$ & Hexose-6-phosphate dehydrogenase/glucose 1-dehydrogenase & 0.429 & Cytoplasm \\
\hline$P R K C A$ & Protein kinase $\mathrm{C}$ alpha & 0.439 & Cytoplasm \\
\hline GRN & Granulin precursor & 0.439 & Extracellular space \\
\hline NOP58 & NOP58 ribonucleoprotein & 0.455 & Nucleus \\
\hline mir-449 & microRNA 449a & 0.457 & Cytoplasm \\
\hline$N M B$ & Neuromedin B & 0.459 & Extracellular space \\
\hline \multicolumn{4}{|l|}{ Up-regulated } \\
\hline RBBP4 & RB binding protein 4 , chromatin remodeling factor & 3.65 & Nucleus \\
\hline CNOT7 & CCR4-NOT transcription complex subunit 7 & 3.21 & Nucleus \\
\hline EXT2 & Exostosin glycosyltransferase 2 & 2.93 & Cytoplasm \\
\hline$P T K 2$ & Protein tyrosine kinase 2 & 2.58 & Cytoplasm \\
\hline$P H B$ & Prohibitin & 2.36 & Nucleus \\
\hline$R A B 11 B$ & RAB11B, member RAS oncogene family & 2.32 & Cytoplasm \\
\hline$A R F I P 2$ & ADP ribosylation factor interacting protein 2 & 2.23 & Cytoplasm \\
\hline GNB2 & G protein subunit beta 2 & 2.11 & Plasma membrane \\
\hline$B C L 2 L 2$ & BCL2 like 2 & 2.08 & Cytoplasm \\
\hline SERPINE1 & Serpin family E member 1 & 1.99 & Extracellular space \\
\hline
\end{tabular}

Table V. The 10 most significant canonical pathways regulated by PEITC compared to DMSO in LNCaP Setd7-KD cell. Genes in bold are downregulated in the PEITC treatment.

\begin{tabular}{|c|c|c|c|}
\hline Canonical pathways & $\begin{array}{c}\text {-Log } \\
(p \text {-Value })\end{array}$ & Ratio & Target genes \\
\hline tRNA charging & 2.42 & $7 / 35(0.200)$ & CARS, RARS2, HARS, LARS2, TARS, AARS, EPRS \\
\hline Glutaryl-CoA degradation & 1.63 & $3 / 11(0.273)$ & ACAT2, HSD17B4, HADH \\
\hline $\begin{array}{l}\text { Phosphatidylethanolamine } \\
\text { biosynthesis II }\end{array}$ & 1.51 & $2 / 5(0.400)$ & $C E P T 1, P I G F$ \\
\hline Aspartate degradation II & 1.51 & $2 / 5(0.400)$ & GOT1, MDH2 \\
\hline Glioma signaling & 1.44 & $10 / 89(0.122)$ & $C D K N 2 A, R A F 1, I G F 2, I R S 1, C D K N 1 A, I G F 1 R, E G F, M D M 2, C D K N 2 B, P R K C A$ \\
\hline $\begin{array}{l}\text { Tryptophan degradation } \\
\text { III (Eukaryotic) }\end{array}$ & 1.43 & $3 / 13(0.231)$ & $A C A T 2, H S D 17 B 4, H A D H$ \\
\hline $\begin{array}{l}\text { Nur77 Signaling in } \\
\text { T lymphocytes }\end{array}$ & 1.42 & $5 / 32(0.156)$ & $H L A-D R B 1, C A S P 3, M E F 2 D, N R 4 A 1, C Y C S$ \\
\hline $\begin{array}{l}\text { Hepatic fibrosis/Hepatic } \\
\text { stellate cell activation }\end{array}$ & 1.41 & $10 / 90(0.111)$ & SMAD2, IGF2, FN1, TIMP1, SMAD7, IGF1R, EGF, ECE1, SERPINE1, AGT \\
\hline Unfolded protein response & 1.33 & $6 / 45(0.133)$ & SEL1L, SCAP, PDIA6, VCP, CANX, NFE2L2 \\
\hline $\begin{array}{l}\text { Superpathway of } \\
\text { cholesterol biosynthesis }\end{array}$ & 1.25 & $4 / 25(0.160)$ & SQLE, ACAT2, DHCR24, HMGCS1 \\
\hline
\end{tabular}

Top differentially expressed genes and canonical pathways modulated by PEITC in LNCaP Setd7 KD cells. To further determine differentially expressed genes in LNCaP Setd7-KD cells treated with PEITC or DMSO, we identified the top 10 down-regulated or up-regulated genes which are shown in
Table IV. A fold change less than 1 indicates that the expression of the gene was decreased by PEITC treatment compared to the expression in the control group, whereas a fold change greater than 1 indicates elevated expression in PEITC-treated LNCaP Setd7-KD cells. Among the top 10 


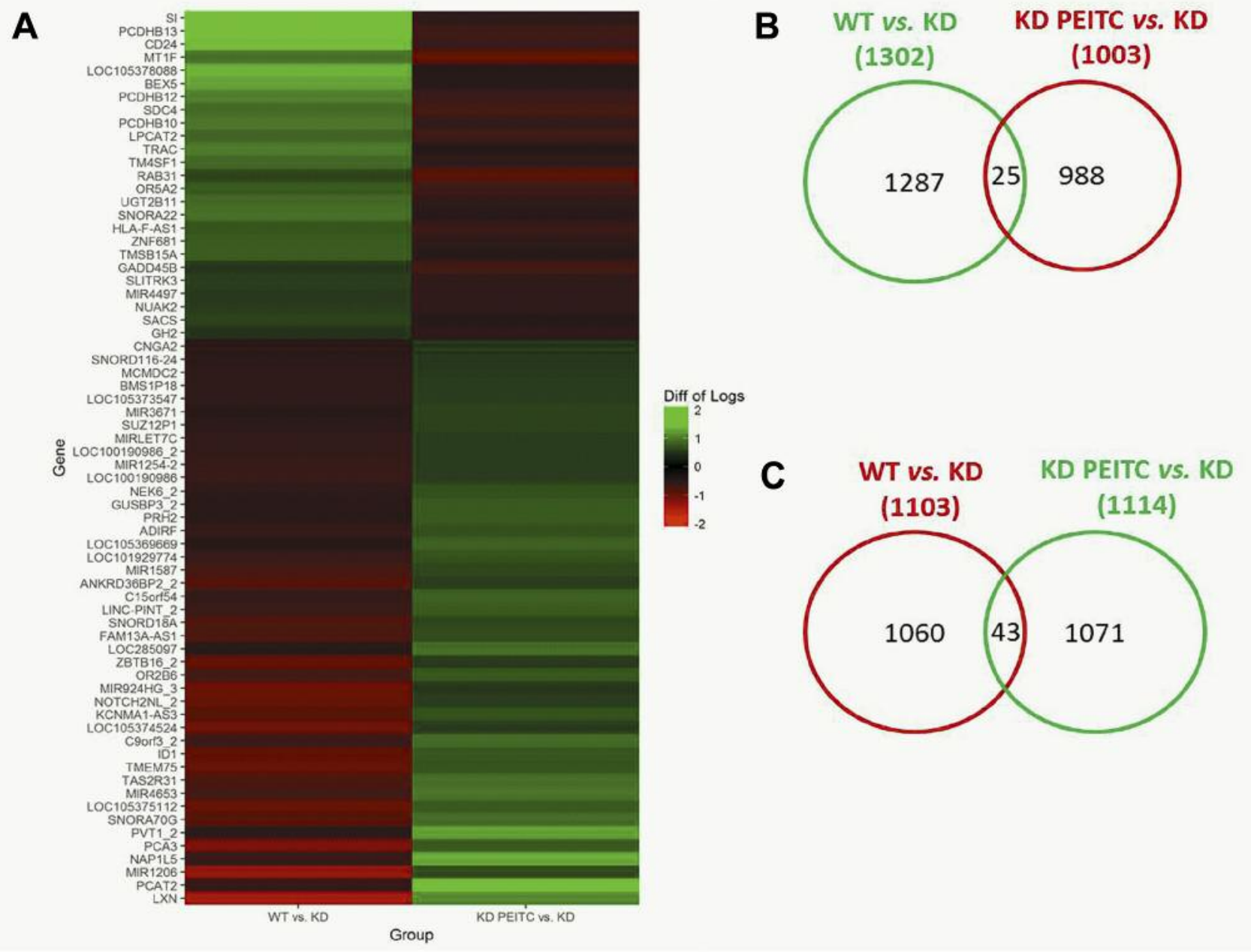

Figure 3. Overview of the genes regulated by Setd7 knockdown and PEITC treatment. (A) Heat map of 68 genes with differential expression that appeared in $W T$ versus $K D$ group and KD PEITC versus KD group. $(B, C)$ Venn diagrams comparing the up-regulated and down-regulated genes between $W T$ versus KD group and KD PEITC versus KD group. Genes with log 2 fold changes greater than 0.5 were counted. WT, LNCaP; KD, LNCaP Setd7-KD.

genes down-regulated by PEITC in the absence of Setd7, Timp1, Tnks, Hla-drb1, Gnai2, and H6pd were downregulated by more than 2.3 -fold, and of the top 10 upregulated genes, Rbbp4, Cnot7, Ext2, Ptk2, Phb, and Rabl1b were up-regulated by at least 2.3 -fold relative to their expression in the DMSO-treated Setd7-KD group. In addition, canonical pathway analysis was performed using IPA software. A total of 274 canonical pathways were significantly associated with the genes differentially expressed between the PEITC treated group and the control DMSO group. The top 10 most significant canonical pathways are shown in Table $\mathrm{V}$ and include "tRNA Charging", "Glutaryl-CoA Degradation", and "Phosphatidylethanolamine Biosynthesis II".

Overview of differentially expressed genes regulated by Setd7 knockdown and PEITC treatment. To examine the impact of
PEITC treatment and Setd7 knockdown in LNCaP cells, the gene expression profiles between wild-type LNCaP cells (WT) and LNCaP Setd7-KD (KD) cells as well as between PEITC-treated KD cells and DMSO-treated KD cells were compared. A cut-off $\log 2$ fold change greater than 0.5 was used to identify the differentially expressed genes. Overall, 2,405 differentially expressed genes were identified between the WT and KD group (1,302 genes were down-regulated by Setd7 knockdown, and 1,103 genes were up-regulated by Setd7 knockdown). A total of 2,117 differentially expressed genes were also observed between the PEITC-treated KD group and the DMSO-treated KD group $(1,114$ genes were up-regulated by PEITC treatment, and 1,003 genes were down-regulated by PEITC treatment) (Figure 3). Among the genes regulated by Setd7 knockdown and by PEITC treatment of LNCaP Setd7-KD cells, a total of 68 genes were 
sI

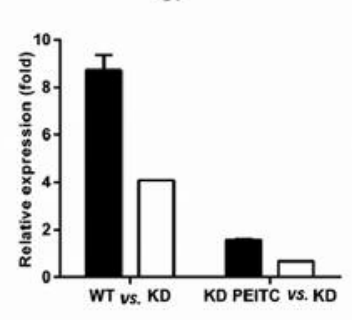

ID1

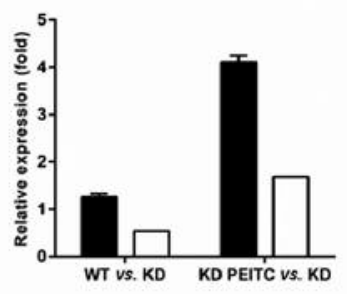

RAB31

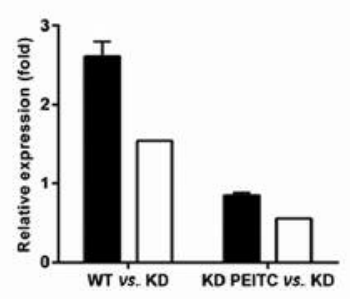

PCDHB13

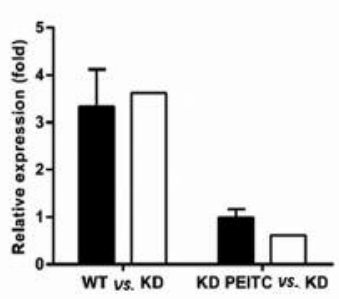

GADD45B

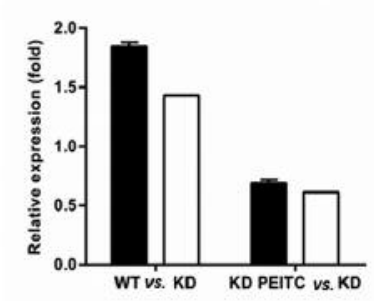

GH2

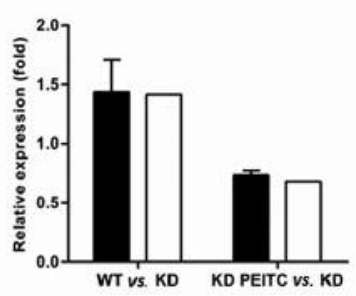

CD24

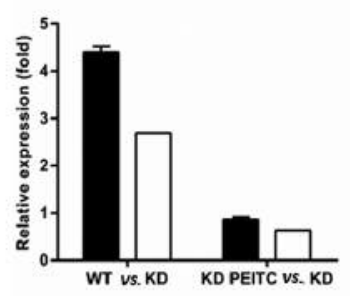

SACS

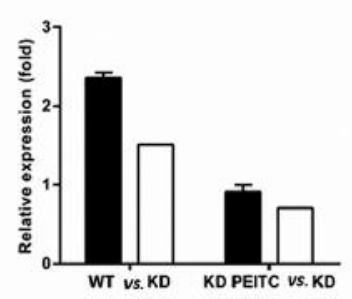

SDC4

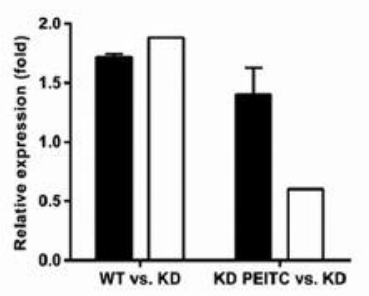

LXN

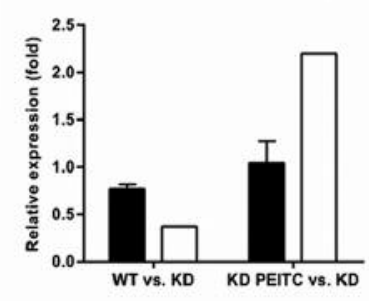

\section{- qPCR}

$\square$ Microarray

Figure 4. Validation of the mRNA changes of selected genes regulated by Setd7 knockdown and PEITC treatment. mRNA isolated from WT, KD, and KD PEITC groups was subjected to qPCR analysis. Black bar: the qPCR results are presented as the fold changes of WT versus KD group and KD PEITC versus KD group using Gapdh as the endogenous control. White bar: fold change from the microarray analysis. The bars represent the mean values of triplicate samples (mean $\pm S D$ ). WT, LNCaP; KD, LNCaP Setd7-KD.

changed in the same direction. Specifically, 25 genes were down-regulated by Setd7 KD $(25 / 1,302)$ compared to the WT group; these genes were also down-regulated in the PEITC-treated KD group $(25 / 1,003)$ compared to the KD group. Forty-three up-regulated genes in the KD group $(43 / 1,103)$ were also up-regulated by PEITC treatment $(43 / 1,114)$. As shown in the heat map (Figure 3A), the 68 genes commonly differentially expressed by Setd7 KD and by PEITC treatment in Setd7-KD cells include the following 3 types of non-coding RNAs: microRNA, long non-coding RNA, and small nucleolar RNA. This result suggests that some of the non-coding RNAs are modulated by Setd7 knockdown and by PEITC treatment in Setd7-KD cells and that they may have relevant functions in chemoprevention. We selected 18 genes from the 68 shared genes and validated their expression in the WT, KD, and PEITC-treated KD groups by qPCR (Figure 4, black bars). The microarray findings were confirmed in fifty-six percent (10 out of 18 selected genes) of the tested genes (Figure 4, white bars).
Even though the fold changes deduced from the qPCR results in the expression of Si (KD PEITC vs. KD), SDC4 (KD PEITC vs. KD), and ID1 (KD vs. WT) were not consistent with those from the microarray results, the trend was to the same direction. According to the qPCR and microarray results, among these 10 genes, $P c d h b 13, C d 24$, $S d c 4$, Gadd45b, Sacs, Rab31, and Gh2 were up-regulated in the KD versus the WT group but decreased in the KD PEITC versus KD group. Furthermore, according to the $\mathrm{qPCR}$ and microarray results, the mRNA expression levels of $I d l$ and Lxn were decreased in the KD versus the WT group but increased in the KD PEITC versus KD group (Figure 4).

Top differentially expressed genes and canonical pathways modulated by PEITC in LNCaP cells. To determine the impact of PEITC on the transcriptome of LNCaP cells, the gene expression profiles of the PEITC-treated group were compared with those of the control DMSO-treated group. A total of 217 differentially expressed genes showed a $\log 2$ 
Table VI. Top 10 down-regulated and up-regulated genes in LNCaP cells treated with PEITC compared to DMSO group. The expression of the genes in the DMSO group was set to 1 .

\begin{tabular}{|c|c|c|c|}
\hline Gene ID & Gene name & Fold Change & Location \\
\hline \multicolumn{4}{|c|}{ Down-regulated } \\
\hline$S L C 25 A 3$ & Solute carrier family 25 member 3 & 0.366 & Cytoplasm \\
\hline$L A M C 1$ & Laminin subunit gamma 1 & 0.405 & Extracellular space \\
\hline$C D C 14 B$ & Cell division cycle 14B & 0.426 & Nucleus \\
\hline ATP5C1 & ATP synthase & 0.505 & Cytoplasm \\
\hline$H S D 17 B 7$ & Hydroxysteroid 17-beta dehydrogenase 7 & 0.51 & Cytoplasm \\
\hline IGHAI & Immunoglobulin heavy constant alpha 1 & 0.513 & Extracellular space \\
\hline mir-130 & microRNA $130 \mathrm{a}$ & 0.515 & Cytoplasm \\
\hline ST13 & ST13, Hsp70 interacting protein & 0.515 & Cytoplasm \\
\hline$M I N P P 1$ & Multiple inositol-polyphosphate phosphatase 1 & 0.521 & Cytoplasm \\
\hline DARS & Aspartyl-tRNA synthetase & 0.524 & Cytoplasm \\
\hline \multicolumn{4}{|c|}{ Up-regulated } \\
\hline mir-515 & MicroRNA 520c & 2.81 & Cytoplasm \\
\hline NUDT5 & Nudix hydrolase 5 & 2.17 & Cytoplasm \\
\hline CLDN12 & Claudin 12 & 2.13 & Plasma membrane \\
\hline PDPK1 & 3-phosphoinositide dependent protein kinase 1 & 2.07 & Cytoplasm \\
\hline$B C L 2 L 2$ & BCL2 like 2 & 2.07 & Cytoplasm \\
\hline$A M F R$ & Autocrine motility factor receptor & 2.06 & Plasma Membrane \\
\hline$R R M 2 B$ & Ribonucleotide reductase regulatory TP53 inducible subunit M2B & 2.04 & Nucleus \\
\hline$A B C B 9$ & ATP binding cassette subfamily B member 9 & 2.04 & Cytoplasm \\
\hline CD59 & CD59 molecule (CD59 blood group) & 2.03 & Plasma Membrane \\
\hline SENP2 & SUMO1/sentrin/SMT3 specific peptidase 2 & 2.01 & Nucleus \\
\hline
\end{tabular}

fold change greater than 0.5 . The top 10 down-regulated and top 10 up-regulated genes in this comparison are presented in Table VI. Of the top 10 down-regulated genes, Slc25a3, Lamc1, $C d c 14 b$ were down-regulated by more than 2.3 -fold upon PEITC treatment. Among the top 10 up-regulated genes, mir-515, Nudt5, Cldn12 were up-regulated by 2.1 -fold or higher upon PEITC treatment. IPA was used to analyze the canonical pathways regulated by PEITC. We identified a total of 341 canonical pathways significantly associated with the differentially expressed genes in the PEITC-treated group compared with the control DMSO group. The top 10 most significant canonical pathways are displayed in Table VII. Interestingly, "Cancer Drug Resistance by Drug Efflux", "PI3K/AKT Signaling", and "PTEN Signaling" are listed in the top 10 canonical pathways. The up-regulated gene $P d p k 1$ and the down-regulated gene $N f k b l$ are strictly related to these pathways.

Overview of differentially expressed genes regulated by PEITC treatment compared with the control DMSO group in LNCAP cells and in LNCaP Setd7-KD cells. Differential gene expression profiling after treatment of $\mathrm{LNCaP}$ cells and in LNCaP Setd7 KD cells with PEITC was next examined by comparing: the PEITC-treated WT cells versus DMSOtreated WT cells and the PEITC-treated KD cells versus DMSO-treated KD cells. A $\log _{2}$ fold change cut-off of 0.5 was used to identify the differentially expressed genes. A total of 1,998 differentially expressed genes were identified in the comparison of the PEITC-treated WT versus DMSOtreated WT group $(1,079$ genes were up-regulated by PEITC treatment, and 919 genes were down-regulated by PEITC treatment). Furthermore, 2,117 differentially expressed genes were identified in the comparison of the PEITC-treated KD versus untreated KD group $(1,114$ genes were up-regulated by PEITC treatment, and 1,003 genes were down-regulated by PEITC treatment) (Figure 5). Of the genes regulated by PEITC treatment, expression of a total of 76 genes was found to be affected in opposite directions. Specifically, 48 genes that were significantly up-regulated by PEITC treatment in WT cells $(48 / 1,079)$ were down-regulated by PEITC treatment in KD cells $(48 / 1,003)$. Twenty-eight significantly down-regulated genes in the PEITC-treated WT group (28/919) were increased by PEITC treatment in the KD group $(28 / 1,114)$. These 76 genes might represent a set of molecular targets that explain the differences between PEITC-treated wild-type LNCaP cells and Setd7-KD cells, indicating that Setd7 may play an important role in the chemopreventive effects of PEITC in PCa cells. Given the potential function of the genes presented in Figure 5, 16 genes were selected for further validation by qPCR (black bars). Seventy-five percent (12 out of 16 selected genes) of genes tested by qPCR confirmed microarray findings (white 
Table VII. The 10 most significant canonical pathways regulated by PEITC compared to DMSO in LNCaP cell. Genes in bold are down-regulated in the PEITC treatment.

\begin{tabular}{|c|c|c|c|}
\hline Canonical pathways & $\begin{array}{c}\text {-Log } \\
(p \text {-Value })\end{array}$ & Ratio & Target genes \\
\hline $\begin{array}{l}\text { Cancer drug resistance } \\
\text { by drug efflux }\end{array}$ & 4.11 & $9 / 36(0.25)$ & mir-154, mir-130, PIK3CA, RRAS2, mir-181, RRAS, PTGS2, NFKB1, mir-27 \\
\hline $\begin{array}{l}\text { Agrin interactions at } \\
\text { neuromuscular junction }\end{array}$ & 3.39 & $9 / 44(0.205)$ & LAMC1, PAK1, RRAS2, RRAS, ITGA2, RAC1, ITGA5, ACTG1, CTTN \\
\hline PI3K/AKT signaling & 2.9 & $13 / 94(0.138)$ & $\begin{array}{l}\text { PIK3CA, CDC37, RRAS2, RRAS, ITGA2, YWHAZ, } \\
I L K, I T G A 5, P D P K 1, P T G S 2, G S K 3 B, N F K B 1, B C L 2\end{array}$ \\
\hline $\begin{array}{l}\text { Tetrahydrofolate salvage } \\
\text { from } 5,10 \text {-methenyltetra- } \\
\text { hydrofolate }\end{array}$ & 2.87 & $3 / 5(0.6)$ & MTHFD1, MTHFD2L, GART \\
\hline PTENsignaling & 2.7 & $12 / 87(0.138)$ & $\begin{array}{c}P I K 3 C A, R R A S 2, R R A S, T G F B R 3, I T G A 2, R A C 1, I L K, \\
I T G A 5, P D P K 1, G S K 3 B, N F K B 1, B C L 2\end{array}$ \\
\hline PAK signaling & 2.64 & $10 / 66(0.152)$ & PAK1, PIK3CA, RRAS2, RRAS, ITGA2, RAC1, ITGA5, LIMK2, NCK1, GIT1 \\
\hline $\begin{array}{l}\text { CCR3 signaling } \\
\text { in eosinophils }\end{array}$ & 2.55 & $11 / 79(0.139)$ & $\begin{array}{c}P A K 1, P I K 3 C A, R R A S 2, R R A S, R A C 1, \text { GNB5, } \\
\text { PPP1CB, LIMK2, PLA2G2A, PLA2G12A, PRKCA }\end{array}$ \\
\hline Paxillin signaling & 2.5 & $10 / 69(0.145)$ & PAK1, PIK3CA, RRAS2, ARFIP2, RRAS, ITGA2, RAC1, ITGA5, NCK1, ACTG1 \\
\hline $\begin{array}{l}\text { Role of MAPK signaling } \\
\text { in the pathogenesis } \\
\text { of influenza }\end{array}$ & 2.41 & $7 / 39(0.179)$ & RRAS2, RRAS, PTGS2, PLA2G2A, PLA2G12A, BCL2, PRKCA \\
\hline Rac signaling & 2.3 & $11 / 85(0.129)$ & $\begin{array}{l}\text { ACTR2, PAK1, PIK3CA, RRAS2, ARFIP2, RRAS, } \\
\text { ITGA2, RAC1, ITGA5, LIMK2, NFKB1 }\end{array}$ \\
\hline
\end{tabular}

bars). Among these 12 genes, the relative mRNA expression of Lrrtm1, Fcrl6, Thsd7a, Apom, Armc12, Tktl1, and Zfp235 was increased in PEITC-treated WT cells, whereas Setd7 knockdown prevented this induction. Furthermore, the mRNA expression levels of Tpm3, Or9a2, Dcaf4l1, Cbln2, and Tas2r19 were all decreased in PEITC-treated WT cells, but Setd7 knockdown prevented this suppression (Figure 6).

\section{Discussion}

In the current study, the impact of the epigenetic modifier histone methyltransferase Setd7 KD and the biological effects of PEITC were investigated in LNCaP PCa cells. Accumulating evidence suggests that Setd7 can influence chromatin conformation and transcriptional activity in a number of ways. PEITC has been shown to possess therapeutic effects in vitro and in vivo, including anticancer, antioxidant, and anti-inflammatory activities, and it may prevent PCa through epigenetic modifications. Therefore, it is of great interest to explore the role of Setd7 in PEITCtreated PCa cells by obtaining transcriptome profiles with oligonucleotide microarray analysis. Notably, Setd7 knockdown was found to dramatically affect the transcriptome profiles of $\mathrm{LNCaP}$ cells and to influence the expression of a higher number of genes and with greater fold changes than PEITC treatment.

The top 10 up-regulated and top 10 down-regulated genes presented in the tables, offer new insights into the discovery of important genes driving $\mathrm{PCa}$, and may also suggest potential candidate therapeutic targets and biomarkers for the prevention, treatment and/or diagnosis of $\mathrm{PCa}$. To our surprise, when Setd7 expression was inhibited in LNCaP cells, the tumor suppressor gene Rarres3 (retinoic acid receptor responder 3) was up-regulated with a notably large fold change (28.06) (Table II). Rarres3 was reported to be down-regulated by Esrrb (estrogen related receptor $\beta$ ) and by its synthetic ligand DY131 in PCa DU145 cells based on RNA-seq analysis (32). Additionally, using RNA sequencing, a recent work demonstrated that Rarres3 can be epigenetically silenced by the histone methyltransferase G9a, which promotes liver cancer development (33).

Among the top regulated genes in PEITC-treated LNCaP Setd7-KD cells, Rbbp4 (RB binding protein 4, chromatin remodeling factor) is the most significantly up-regulated gene (fold change $=3.65$, Table IV). Rbbp4 is a component of co-repressor complexes involved in histone deacetylation and chromatin assembly that lead to transcriptional repression. Rbbp4 can also regulate cell proliferation. When Rbbp4 is overexpressed in LNCaP cells, it induces cell death (34). Nevertheless, no studies have been performed addressing the relationship between PEITC and Rbbp4 in PCa. Our results indicated that the role of Rbbp4 in cells treated with PEITC may be worth exploring in PCa cells. Of the genes that were most significantly up-regulated in PEITC-treated LNCaP cells, miR-515 (fold change=2.81, Table VI) has been reported as a tumor suppressor in breast cancer and non- 
A

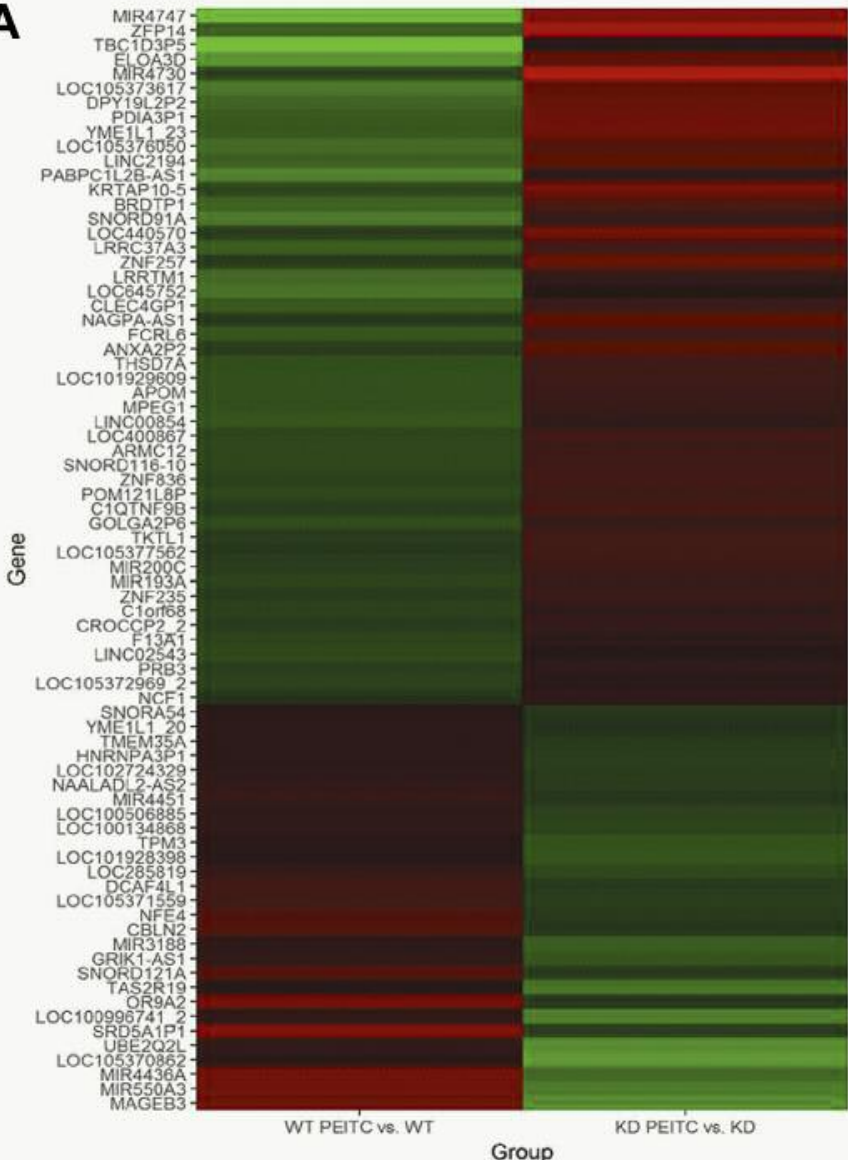

B

WT PEITC vs. WT KD PEITC vs. KD

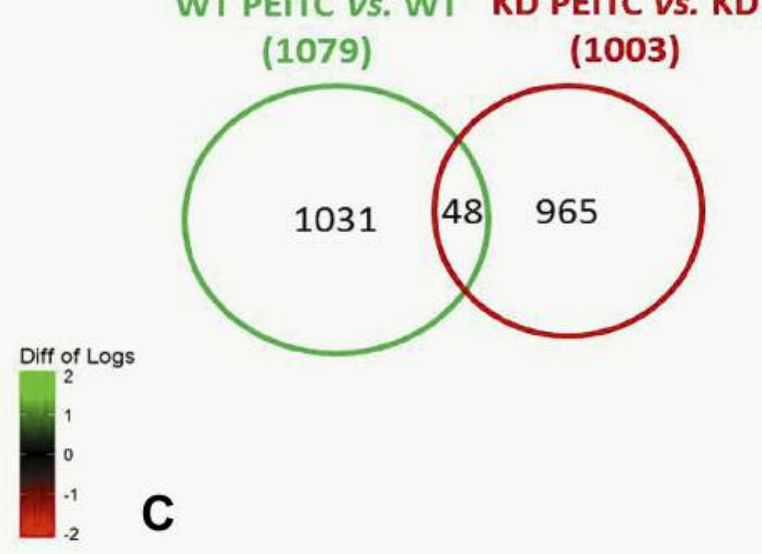

WT PEITC vs. WT KD PEITC vs. KD

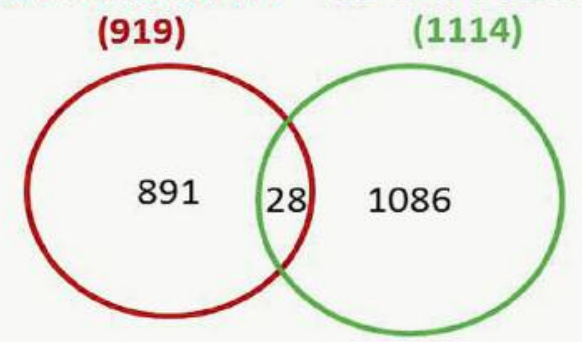

Figure 5. Overview of the genes regulated by PEITC treatment in WT and KD groups. (A) Heat map of 76 genes with differential expression that appeared in WT PEITC versus WT group and KD PEITC versus KD group. $(B, C)$ Venn diagrams comparing the up-regulated and down-regulated genes between WT PEITC versus WT group and KD PEITC versus KD group. Genes with log 2 fold changes greater than 0.5 were counted. WT, $L N C a P ; K D, L N C a P$ Setd $7-K D$.

small cell lung cancer (NSCLC) based on its inhibition of proliferation and induction of apoptosis $(35,36)$. miR-515$5 \mathrm{p}$ is transcriptionally repressed by $\mathrm{ER} \alpha$ and can directly target Mark4 to lead to inhibition of cancer cell migration and metastasis (35). Clinical data have shown that high miR515-5p and low Mark4 expression are associated with increased survival of breast and lung cancer patients (36). Overall, these in vivo and in vitro results strongly suggest that PEITC may play a crucial role in PCa prevention by perturbing the molecular targets newly identified in our study, such as miR-515.

The most significantly affected canonical pathway regulated by Setd7 knockdown in LNCaP cells is "Death Receptor Signaling" (Table III). Death receptors have an approximately 80-amino-acid-long death domain in the cytoplasmic portion, and form a subgroup within the TNFR (tumor necrosis factor receptor) superfamily (37). The TNFR superfamily includes more than 20 proteins and functions in the immune system. Our results showed that 5 of the 27 molecules in "Death Receptor Signaling" are downregulated, whereas other molecules, such as the NF-kBrelated and TNF-related genes, are up-regulated. Of the 5 down-regulated molecules, Ikbkb, a subunit of IkB kinase, triggers immune responses associated with cytokineactivated intracellular pathways. Additionally, Ikbkb can activate NF-kB. Notably, Ikbkb belongs also in other significant canonical pathways, such as "TNFR2 Signaling", "Acute Phase Response Signaling", "Neuroinflammation Signaling Pathway", "TNFR1 Signaling”, "Role of RIG1like Receptors in Antiviral Innate Immunity", and "Induction of Apoptosis by HIV1". TRAF2 directly interacts with TNF receptors and forms complexes with other Traf proteins. Traf2 is required for the TNF $\alpha$-mediated activation of Mapk8/Jnk and NF-kB. Correspondingly, our preliminary 

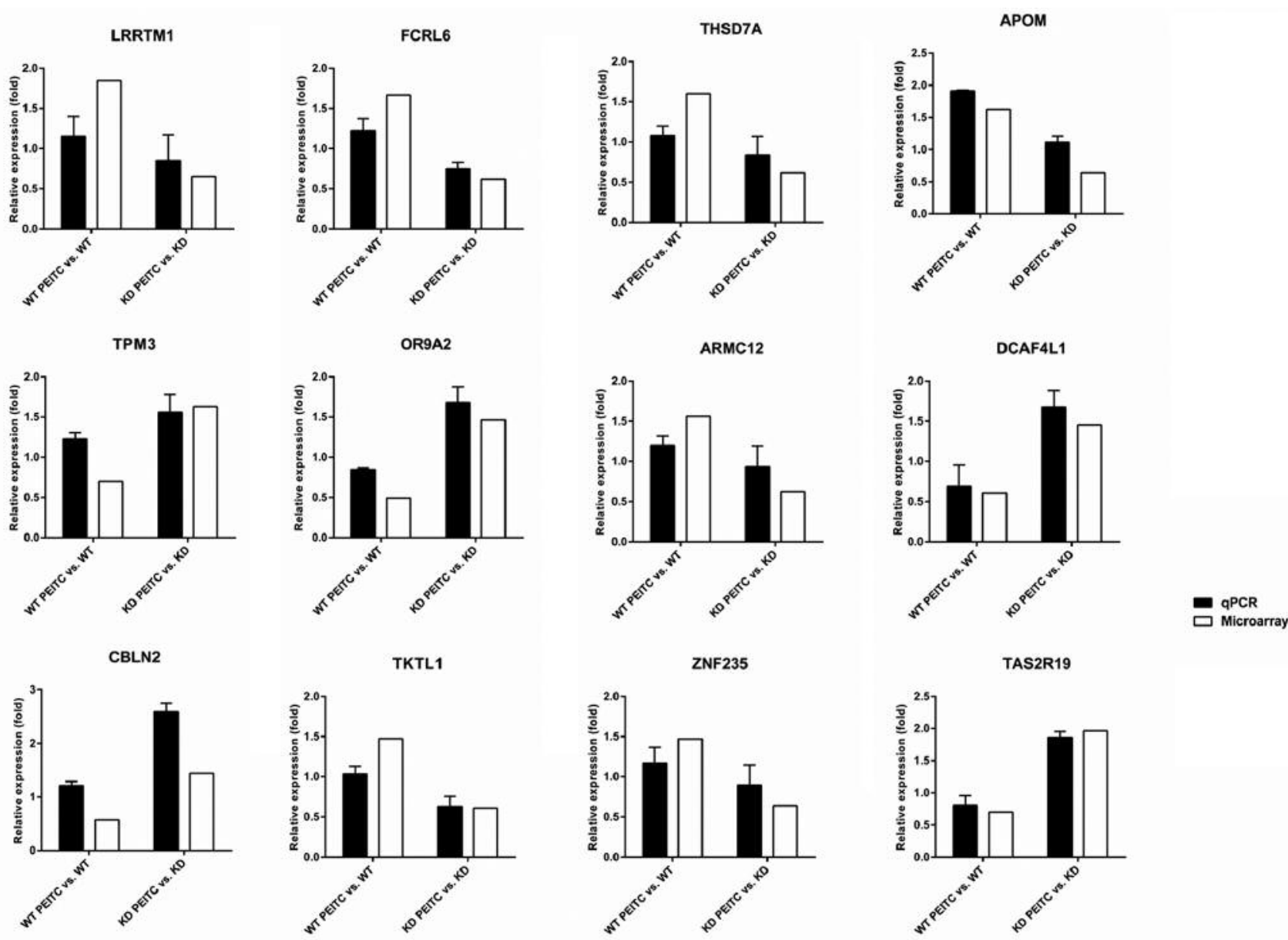

Figure 6. Validation of the mRNA changes of selected genes regulated by PEITC treatment. mRNA isolated from WT, KD, WT PEITC and KD PEITC groups was subjected to qPCR analysis. Black bar: the qPCR results are presented as fold changes of WT PEITC versus WT group and KD PEITC versus KD group using Gapdh as the endogenous control. White bar: fold changes from the microarray analysis. The bars represent the mean values of triplicate samples (mean $\pm S D)$. WT, LNCaP; KD, LNCaP Setd7-KD.

data showed that Setd7 knockdown in LNCaP cells dramatically elevates the expression of inflammatory genes such as TNF. A previous study has shown that Setd7 deficiency prolongs the DNA binding of NF-kB and induces $\mathrm{TNF} \alpha$-mediated expression of NF-kB target genes (24). Together, our results further indicate the negative regulation of NF-kB-mediated inflammatory responses by Setd7 and suggest additional potential targets of Setd7 in LNCaP cells. Another canonical pathway highlighted by Setd7 knockdown was "Agrin Interactions at Neuromuscular Junction" (Table III). Interestingly, this pathway was also identified as the most significant pathway affected by PEITC in LNCaP cells (Table VII). In addition, the canonical pathways most impacted by PEITC in LNCaP Setd7-KD cells are distinct from those regulated by PEITC treatment in wild-type LNCaP cells or those perturbed by Setd7 knockdown alone (Tables III, V, and VII). These results indicate that Setd7 has an impact on PEITC-regulated genes in LNCaP cells as well. Additionally, a total of 76 genes showed altered expression in opposite directions after PEITC treatment in wild-type LNCaP cells or in Setd7-KD LNCaP cells (Figure 5). Other studies have also shown changes in some of these genes (Figure 6) including Fcrl6 (38), Thsd7a (39), Apom (40), Mpegl (41), and Tktll (42, 43). Tktl1 has been reported as a potential biomarker for PCa. The expression of Tkt11 is increased in monocytes of tumor patients and decreased in the serum of PCa patients (44). Another recent study has shown that surgical removal of prostate primary tumors resulted in the significant inhibition of Tktl1 in macrophages (45). Our observations expand the suggestion that cross-talk might occur between Setd7 and Tktl1 in PCa cells exposed to chemopreventive compounds such as PEITC. We also noticed non-coding RNAs in our list, including microRNAs, long non-coding RNAs, and small nucleolar RNAs. A 
growing body of evidence suggests that the non-coding RNAs play a crucial role in modulating fundamental biological processes. For instance, a recent study demonstrated that the long non-coding RNA LOC283070 induces the transition of LNCaP cells into androgenindependent cells, possibly through Camk1d (46). From our observations, it is worth noting that the pseudogene Pdia3p1, a long non-coding RNA, is up-regulated by PEITC in LNCaP cells but down-regulated in LNCaP Setd7-KD cells. A recent in vivo and in vitro study demonstrated that Pdia3p1 promotes the progression of hepatocellular carcinoma and increases tumor proliferation while suppressing apoptosis through the regulation of the p53 signaling pathway in hepatocellular carcinoma cells. Pdia3p1 acts as an oncogene and a possible prognostic marker in hepatocellular carcinoma (47). Interestingly, our data showed that PEITC induced the expression of Pdia3p1 in LNCaP cells, which was prevented by Setd 7 knockdown. Together, these results indicate that Setd7 may play an important role in LNCaP cells exposed to PEITC by regulating Pdia3p1 expression.

In addition, a subset of 68 genes that were differentially expressed in the same direction by Setd 7 knockdown in wild-type LNCaP cells and by combined PEITC treatment and Setd7 knockdown were identified (Figure 3). The altered expression of some of these genes was confirmed by qPCR analysis (Figure 4). Alterations of several genes were noticed in our list, including Rab31 (48), Gadd45b (49), Adirf (50), Idl (51), Pca3 (52), and Pcnt2 (53). Rab31 is a member of the monomeric GTP-binding proteins, that play essential roles in intracellular vesicle and granule transport (54) Rab31 influences cancer progression and is associated with various types of cancer (48). Our results supply further evidence that Rab31 can be inhibited by Setd7 knockdown in LNCaP cells with or without PEITC treatment. Also, two other targets, Pca3 and Pcat2, which are affiliated with the non-coding RNA class, attracted our attention. Pca3 is used as a urine-based PCa marker because it is only expressed in human prostate tissue and is highly overexpressed in $\mathrm{PCa}$ (55-57). The most commonly used biomarker for $\mathrm{PCa}$ is serum prostate-specific antigen (PSA), but Pca3 has a higher specificity and a better positive and negative predictive value (58). In addition, Pca3 knockdown can significantly suppress epithelial ovarian carcinoma cells and $\mathrm{LNCaP}$ cell proliferation, migration, and invasion and might be a novel diagnostic biomarker of epithelial ovarian carcinoma and a potential therapeutic target for inhibiting PCa $(52,59)$. However, these results are not in accordance with our observations because Setd7 knockdown and PEITC treatment both elevate the expression of Pca3 in LNCaP cells. Thus far, many conflicting results have been obtained regarding $\mathrm{Pca} 3$ in $\mathrm{PCa}$, including its correlation with adverse tumor volume, grading (Gleason score), and extracapsular extension (60-62).
Our study provided the first quantitative gene expression profiling of Setd7-knockdown and PEITC treatment in PCa LNCaP cells. Altered biological pathways impacted by Setd7 KD and PEITC treatment were identified. A set of these genes are considered possible molecular targets involved in the prevention and treatment of PCa. These findings offer new insights on the molecular mechanisms underlying Setd7 and PEITC treatment in PCa which could be translated to the clinical setting.

\section{Conflicts of Interest}

The Authors declare no conflicts of interest regarding this study.

\section{Acknowledgements}

This work is supported in part by institutional funds and by AT009152 from the National Center for Complementary and Integrative Health (NCCIH), R01AT007065 from NCCIH and the Office of Dietary Supplements (ODS) and CA200129 from the National Cancer Institute (NCI). The authors thank all the members in Dr. Kong's lab and Christian Bixby in RUCDR Infinite Biologics for their helpful discussion of this work.

\section{References}

1 Wang LG and Chiao JW: Prostate cancer chemopreventive activity of phenethyl isothiocyanate through epigenetic regulation (review). Int J Oncol 37(3): 533-539, 2010.

2 Kolonel LN, Hankin JH, Whittemore AS, Wu AH, Gallagher RP, Wilkens LR, John EM, Howe GR, Dreon DM, West DW and Paffenbarger RS Jr.: Vegetables, fruits, legumes and prostate cancer: A multiethnic case-control study. Cancer Epidemiol Biomarkers Prev 9(8): 795-804, 2000.

3 Abdull Razis AF and Noor NM: Cruciferous vegetables: Dietary phytochemicals for cancer prevention. Asian Pac J Cancer Prev 14(3): 1565-1570, 2013

4 Zhang C, Shu L, Kim H, Khor TO, Wu R, Li W and Kong AN: Phenethyl isothiocyanate (peitc) suppresses prostate cancer cell invasion epigenetically through regulating microrna-194. Mol Nutr Food Res 60(6): 1427-1436, 2016.

5 Singh SV and Singh K: Cancer chemoprevention with dietary isothiocyanates mature for clinical translational research. Carcinogenesis 33(10): 1833-1842, 2012.

6 Tang L, Zirpoli GR, Guru K, Moysich KB, Zhang Y, Ambrosone $\mathrm{CB}$ and McCann SE: Intake of cruciferous vegetables modifies bladder cancer survival. Cancer Epidemiol Biomarkers Prev 19(7): 1806-1811, 2010.

7 Gupta P, Kim B, Kim SH and Srivastava SK: Molecular targets of isothiocyanates in cancer: Recent advances. Mol Nutr Food Res 58(8): 1685-1707, 2014.

8 Cheung KL and Kong AN: Molecular targets of dietary phenethyl isothiocyanate and sulforaphane for cancer chemoprevention. AAPS J 12(1): 87-97, 2010.

9 Wang D, Upadhyaya B, Liu Y, Knudsen D and Dey M: Phenethyl isothiocyanate upregulates death receptors 4 and 5 and inhibits proliferation in human cancer stem-like cells. BMC Cancer 14: 591, 2014. 
10 Gupta P, Wright SE, Kim SH and Srivastava SK: Phenethyl isothiocyanate: A comprehensive review of anti-cancer mechanisms. Biochim Biophys Acta 1846(2): 405-424, 2014.

11 Boyanapalli SS, Li W, Fuentes F, Guo Y, Ramirez CN, Gonzalez $\mathrm{XP}$, Pung D and Kong AN: Epigenetic reactivation of rassf1a by phenethyl isothiocyanate (peitc) and promotion of apoptosis in lncap cells. Pharmacol Res 114: 175-184, 2016.

12 Barve A, Khor TO, Hao X, Keum YS, Yang CS, Reddy B and Kong AN: Murine prostate cancer inhibition by dietary phytochemicals - curcumin and phenyethylisothiocyanate. Pharm Res 25(9): 2181-2189, 2008.

13 Powolny AA, Bommareddy A, Hahm ER, Normolle DP, Beumer JH, Nelson JB and Singh SV: Chemopreventative potential of the cruciferous vegetable constituent phenethyl isothiocyanate in a mouse model of prostate cancer. J Natl Cancer Inst 103(7): 571-584, 2011.

14 Hudson TS, Perkins SN, Hursting SD, Young HA, Kim YS, Wang TC and Wang TT: Inhibition of androgen-responsive lncap prostate cancer cell tumor xenograft growth by dietary phenethyl isothiocyanate correlates with decreased angiogenesis and inhibition of cell attachment. Int J Oncol 40(4): 1113-1121, 2012.

15 Nishioka K, Chuikov S, Sarma K, Erdjument-Bromage H, Allis CD, Tempst $\mathrm{P}$ and Reinberg D: Set9, a novel histone h3 methyltransferase that facilitates transcription by precluding histone tail modifications required for heterochromatin formation. Genes Dev 16(4): 479-489, 2002.

$16 \mathrm{Li} \mathrm{B}$, Carey M and Workman JL: The role of chromatin during transcription. Cell 128(4): 707-719, 2007.

17 Berger SL: The complex language of chromatin regulation during transcription. Nature 447(7143): 407-412, 2007.

18 Esteve PO, Chin HG, Benner J, Feehery GR, Samaranayake M, Horwitz GA, Jacobsen SE and Pradhan S: Regulation of dnmt 1 stability through set7-mediated lysine methylation in mammalian cells. Proc Natl Acad Sci USA 106(13): 50765081, 2009.

19 Balasubramaniyan N, Ananthanarayanan M and Suchy FJ: Direct methylation of fxr by set7/9, a lysine methyltransferase, regulates the expression of fxr target genes. Am J Physiol Gastrointest Liver Physiol 302(9): G937-947, 2012.

20 Ea CK and Baltimore D: Regulation of nf-kappab activity through lysine monomethylation of p65. Proc Natl Acad Sci USA 106(45): 18972-18977, 2009.

21 Subramanian K, Jia D, Kapoor-Vazirani P, Powell DR, Collins RE, Sharma D, Peng J, Cheng X and Vertino PM: Regulation of estrogen receptor alpha by the set7 lysine methyltransferase. Mol Cell 30(3): 336-347, 2008.

22 Ko S, Ahn J, Song CS, Kim S, Knapczyk-Stwora K and Chatterjee B: Lysine methylation and functional modulation of androgen receptor by set 9 methyltransferase. Mol Endocrinol 25(3): 433-444, 2011.

23 Li Y, Reddy MA, Miao F, Shanmugam N, Yee JK, Hawkins D, Ren B and Natarajan R: Role of the histone h3 lysine 4 methyltransferase, set7/9, in the regulation of nf-kappabdependent inflammatory genes. Relevance to diabetes and inflammation. J Biol Chem 283(39): 26771-26781, 2008.

24 Yang XD, Huang B, Li M, Lamb A, Kelleher NL and Chen LF: Negative regulation of nf-kappab action by set9-mediated lysine methylation of the rela subunit. EMBO J 28(8): 1055-1066, 2009.
25 Fujimaki K, Ogihara T, Morris DL, Oda H, Iida H, Fujitani Y, Mirmira RG, Evans-Molina C and Watada H: Set7/9 enzyme regulates cytokine-induced expression of inducible nitric-oxide synthase through methylation of lysine 4 at histone 3 in the islet beta cell. J Biol Chem 290(27): 16607-16618, 2015.

26 Gaughan L, Stockley J, Wang N, McCracken SR, Treumann A, Armstrong K, Shaheen F, Watt K, McEwan IJ, Wang C, Pestell RG and Robson CN: Regulation of the androgen receptor by set9mediated methylation. Nucleic Acids Res 39(4): 1266-1279, 2011.

27 Sowalsky AG, Xia Z, Wang L, Zhao H, Chen S, Bubley GJ, Balk SP and Li W: Whole transcriptome sequencing reveals extensive unspliced mrna in metastatic castration-resistant prostate cancer. Mol Cancer Res 13(1): 98-106, 2015.

28 Wang C, Shu L, Zhang C, Li W, Wu R, Guo Y, Yang Y and Kong AN: Histone methyltransferase setd7 regulates nrf2 signaling pathway by phenethyl isothiocyanate and ursolic acid in human prostate cancer cells. Mol Nutr Food Res 62: e1700840, 2018.

29 Carvalho BS and Irizarry RA: A framework for oligonucleotide microarray preprocessing. Bioinformatics 26(19): 2363-2367, 2010.

30 Amaratunga D, Cabrera $\mathrm{J}$ and Shkedy Z: Exploration and analysis of DNA microarray and other high-dimensional data. Second edition. Wiley \& Sons, Inc., 2014.

31 Irizarry RA, Hobbs B, Collin F, Beazer-Barclay YD, Antonellis $\mathrm{KJ}$, Scherf U and Speed TP: Exploration, normalization, and summaries of high density oligonucleotide array probe level data. Biostatistics 4(2): 249-264, 2003.

$32 \mathrm{Lu} \mathrm{Y,} \mathrm{Li} \mathrm{J,} \mathrm{Cheng} \mathrm{J} \mathrm{and} \mathrm{Lubahn} \mathrm{DB:} \mathrm{Messenger} \mathrm{rna} \mathrm{profile}$ analysis deciphers new esrrb responsive genes in prostate cancer cells. BMC Mol Biol 16: 21, 2015.

33 Wei L, Chiu DK, Tsang FH, Law CT, Cheng CL, Au SL, Lee JM, Wong CC, Ng IO and Wong CM: Histone methyltransferase g9a promotes liver cancer development by epigenetic silencing of tumor suppressor gene rarres3. J Hepatol 67(4): 758-769, 2017.

34 Cai L, Wang D, Fisher AL and Wang Z: Identification of a genetic interaction between the tumor suppressor eaf 2 and the retinoblastoma protein $(\mathrm{rb})$ signaling pathway in C. Elegans and prostate cancer cells. Biochem Biophys Res Commun 447(2): 292-298, 2014.

35 Pinho FG, Frampton AE, Nunes J, Krell J, Alshaker H, Jacob J, Pellegrino L, Roca-Alonso L, de Giorgio A, Harding V, Waxman J, Stebbing J, Pchejetski D and Castellano L: Downregulation of microrna-515-5p by the estrogen receptor modulates sphingosine kinase 1 and breast cancer cell proliferation. Cancer Res 73(19): 5936-5948, 2013.

36 Pardo OE, Castellano L, Munro CE, Hu Y, Mauri F, Krell J, Lara R, Pinho FG, Choudhury T, Frampton AE, Pellegrino L, Pshezhetskiy D, Wang Y, Waxman J, Seckl MJ and Stebbing J: Mir-515-5p controls cancer cell migration through mark4 regulation. EMBO Rep 17(4): 570-584, 2016.

37 Ashkenazi A and Dixit VM: Death receptors: Signaling and modulation. Science 281(5381): 1305-1308, 1998.

38 Schreeder DM, Pan J, Li FJ, Vivier E and Davis RS: Fcrl6 distinguishes mature cytotoxic lymphocytes and is upregulated in patients with b-cell chronic lymphocytic leukemia. Eur J Immunol 38(11): 3159-3166, 2008.

39 Kuo MW, Wang CH, Wu HC, Chang SJ and Chuang YJ: Soluble thsd7a is an $\mathrm{n}$-glycoprotein that promotes endothelial cell migration and tube formation in angiogenesis. PLoS One 6(12): e29000, 2011. 
40 Burkart KM, Manichaikul A, Wilk JB, Ahmed FS, Burke GL, Enright P, Hansel NN, Haynes D, Heckbert SR, Hoffman EA, Kaufman JD, Kurai J, Loehr L, London SJ, Meng Y, O'Connor GT, Oelsner E, Petrini M, Pottinger TD, Powell CA, Redline S, Rotter JI, Smith LJ, Soler Artigas M, Tobin MD, Tsai MY, Watson K, White W, Young TR, Rich SS and Barr RG: Apom and high-density lipoprotein cholesterol are associated with lung function and per cent emphysema. Eur Respir J 43(4): 10031017, 2014

41 McCormack R and Podack ER: Perforin-2/mpeg1 and other pore-forming proteins throughout evolution. J Leukoc Biol 98(5): 761-768, 2015.

42 Ahopelto K, Bockelman C, Hagstrom J, Koskensalo S and Haglund C: Transketolase-like protein 1 expression predicts poor prognosis in colorectal cancer. Cancer Biol Ther 17(2): 163-168, 2016.

43 Krockenberger M, Engel JB, Schmidt M, Kohrenhagen N, Hausler SF, Dombrowski Y, Kapp M, Dietl J and Honig A: Expression of transketolase-like 1 protein (tktl1) in human endometrial cancer. Anticancer Res 30(5): 1653-1659, 2010.

44 Tsaur I, Thurn K, Juengel E, Oppermann E, Nelson K, Thomas C, Bartsch G, Oremek GM, Haferkamp A, Rubenwolf P and Blaheta RA: Evaluation of tktl1 as a biomarker in serum of prostate cancer patients. Cent European J Urol 69(3): 247-251, 2016.

45 Todenhofer T, Hennenlotter J, Keller G, Neumann T, Stenzl A and Bedke J: Effect of radical prostatectomy on levels of cancer related epitopes in circulating macrophages of patients with clinically localized prostate cancer. Prostate 77(12): 1251-1258, 2017.

46 Wang L, Lin Y, Meng H, Liu C, Xue J, Zhang Q, Li C, Zhang P, Cui $\mathrm{F}$, Chen W and Jiang A: Long non-coding rna loc283070 mediates the transition of lncap cells into androgen-independent cells possibly via camk1d. Am J Transl Res 8(12): 5219-5234, 2016.

47 Kong Y, Zhang L, Huang Y, He T, Zhang L, Zhao X, Zhou X, Zhou D, Yan Y, Zhou J, Xie H, Zhou L, Zheng S and Wang W: Pseudogene pdia3p1 promotes cell proliferation, migration and invasion, and suppresses apoptosis in hepatocellular carcinoma by regulating the p53 pathway. Cancer Lett 407: 76-83, 2017.

48 Grismayer B, Solch S, Seubert B, Kirchner T, Schafer S, Baretton G, Schmitt M, Luther T, Kruger A, Kotzsch M and Magdolen V: Rab31 expression levels modulate tumor-relevant characteristics of breast cancer cells. Mol Cancer 11: 62, 2012.

49 Liu X, Happel C and Ziegelbauer JM: Kaposi's sarcomaassociated herpesvirus micrornas target gadd $45 \mathrm{~b}$ to protect infected cells from cell cycle arrest and apoptosis. J Virol 91(3): pii: e02045-16, 2017.

50 Chen L, Zhou XG, Zhou XY, Zhu C, Ji CB, Shi CM, Qiu J and Guo XR: Overexpression of c10orf116 promotes proliferation, inhibits apoptosis and enhances glucose transport in 3t3-11 adipocytes. Mol Med Rep 7(5): 1477-1481, 2013.

51 Przybyla T, Sakowicz-Burkiewicz M, Maciejewska I, Bielarczyk $\mathrm{H}$ and Pawelczyk T: Suppression of id1 expression in colon cancer cells increases sensitivity to 5-fluorouracil. Acta Biochim Pol 64(2): 315-322, 2017.
52 Liu Y, Zong ZH, Guan X, Wang LL and Zhao Y: The role of long non-coding rna pca3 in epithelial ovarian carcinoma tumorigenesis and progression. Gene 633: 42-47, 2017.

53 Kim T, Cui R, Jeon YJ, Lee JH, Lee JH, Sim H, Park JK, Fadda P, Tili E, Nakanishi H, Huh MI, Kim SH, Cho JH, Sung BH, Peng Y, Lee TJ, Luo Z, Sun HL, Wei H, Alder H, Oh JS, Shim $\mathrm{KS}$, Ko SB and Croce CM: Long-range interaction and correlation between myc enhancer and oncogenic long noncoding rna carlo-5. Proc Natl Acad Sci USA 111(11): 41734178, 2014.

54 Bao X, Faris AE, Jang EK and Haslam RJ: Molecular cloning, bacterial expression and properties of rab31 and rab32. Eur J Biochem 269(1): 259-271, 2002.

55 Bussemakers MJ, van Bokhoven A, Verhaegh GW, Smit FP, Karthaus HF, Schalken JA, Debruyne FM, Ru N and Isaacs WB: Dd3: A new prostate-specific gene, highly overexpressed in prostate cancer. Cancer Res 59(23): 5975-5979, 1999.

56 Neves AF, Araujo TG, Biase WK, Meola J, Alcantara TM, Freitas DG and Goulart LR: Combined analysis of multiple mrna markers by rt-pcr assay for prostate cancer diagnosis. Clin Biochem 41(14-15): 1191-1198, 2008.

57 Loeb S: Does pca3 help identify clinically significant prostate cancer? Eur Urol 54(5): 980-981, 2008.

58 Vlaeminck-Guillem V, Ruffion A and Andre J: Value of urinary pca3 test for prostate cancer diagnosis. Prog Urol 18(5): 259265, 2008.

59 Lemos AE, Ferreira LB, Batoreu NM, de Freitas PP, Bonamino MH and Gimba ER: Pca3 long noncoding rna modulates the expression of key cancer-related genes in lncap prostate cancer cells. Tumour Biol 37(8): 11339-11348, 2016.

60 Nakanishi H, Groskopf J, Fritsche HA, Bhadkamkar V, Blase A, Kumar SV, Davis JW, Troncoso P, Rittenhouse H and Babaian RJ: Pca3 molecular urine assay correlates with prostate cancer tumor volume: Implication in selecting candidates for active surveillance. J Urol 179(5): 1804-1809; discussion 1809-1810, 2008.

61 van Gils MP, Hessels D, Hulsbergen-van de Kaa CA, Witjes JA, Jansen CF, Mulders PF, Rittenhouse HG and Schalken JA: Detailed analysis of histopathological parameters in radical prostatectomy specimens and pca3 urine test results. Prostate 68(11): 1215-1222, 2008.

62 Whitman EJ, Groskopf J, Ali A, Chen Y, Blase A, Furusato B, Petrovics G, Ibrahim M, Elsamanoudi S, Cullen J, Sesterhenn IA, Brassell S, Rittenhouse H, Srivastava S and McLeod DG: Pca3 score before radical prostatectomy predicts extracapsular extension and tumor volume. J Urol 180(5): 1975-1978; discussion 1978-1979, 2008.
Received July 25, 2018

Revised September 19, 2018 Accepted September 28, 2018 